\title{
MTH1 Inhibitor TH1579 Induces Oxidative DNA Damage and Mitotic Arrest in Acute Myeloid Leukemia
}

Kumar Sanjiv ${ }^{1}$, José Manuel Calderón-Montaño', Therese M. Pham¹, Tom Erkers', Viktoriia Tsuber', Ingrid Almlöf', Andreas Höglund', Yaser Heshmati ${ }^{2}$, Brinton Seashore-Ludlow', Akhilesh Nagesh Danda', Helge Gad', Elisee Wiita', Camilla Göktürk', Azita Rasti', Stefanie Friedrich ${ }^{3}$, Anders Centio ${ }^{4,5}$, Montserrat Estruch ${ }^{4,5}$, Thea Kristin Våtsveen ${ }^{6,7}$, Nona Struyf ${ }^{1}$, Torkild Visnes ${ }^{1}$, Martin Scobie', Tobias Koolmeister', Martin Henriksson', Olov Wallner', Teresa Sandvall', Sören Lehmannn ${ }^{2,8}$, Kim Theilgaard-Mönch ${ }^{4,5,9,10}$, Mathew J. Garnett ${ }^{11}$, Päivi Östling', Julian Walfridsson², Thomas Helleday', and Ulrika Warpman Berglund ${ }^{1,12}$

\section{ABSTRACT}

Acute myeloid leukemia (AML) is an aggressive hematologic malignancy, exhibiting high levels of reactive oxygen species (ROS). ROS levels have been suggested to drive leukemogenesis and is thus a potential novel target for treating AML. MTH1 prevents incorporation of oxidized nucleotides into the DNA to maintain genome integrity and is upregulated in many cancers. Here we demonstrate that hematologic cancers are highly sensitive to MTH1 inhibitor TH1579 (karonudib). A functional precision medicine ex vivo screen in primary AML bone marrow samples demonstrated a broad response profile of TH1579, independent of the genomic alteration of AML, resembling the response profile of the standard-of-care treatments cytarabine and doxorubicin. Furthermore, TH1579 killed primary human AML blast cells $\left(\mathrm{CD} 45^{+}\right)$as well as chemotherapy resistance leukemic stem cells $\left(\mathrm{CD} 45^{+} \mathrm{Lin}^{-} \mathrm{CD} 34^{+} \mathrm{CD} 38^{-}\right)$, which

\section{Introduction}

Acute myeloid leukaemia (AML) is an aggressive haematologic malignancy of immature cells of the myeloid lineage. It is the most common acute leukemia in adults, accounting for $75 \%$ of newly diagnosed cases (1). It is highly heterogenetic and stratified into various risk categories based on genetic alterations (2). AML patient samples contain rare leukemic stem cells (LSC), which have unlimited self-renewal capacity that continuously propagates leukemic clones and large numbers of more mature AML blast cells $(3,4)$. Without

${ }^{1}$ Science for Life Laboratory, Department of Oncology-Pathology, Karolinska Institutet, Stockholm, Sweden. ${ }^{2}$ Center for Hematology and Regenerative Medicine, Department of Medicine, Karolinska Institutet, Karolinska University Hospital, Stockholm, Sweden. ${ }^{3}$ Science for Life Laboratory, Department of Biochemistry and Biophysics, Stockholm University, Stockholm, Sweden. ${ }^{4}$ The Finsen Laboratory, Rigshospitalet/National University Hospital, Faculty of Health and Medical Sciences, University of Copenhagen, Copenhagen, Denmark. ${ }^{5}$ Biotech Research and Innovation Center, Faculty of Health and Medical Sciences, University of Copenhagen, Copenhagen, Denmark. ${ }^{6}$ Department for Cancer Immunology, Institute for Cancer Research, Oslo University Hospital, Oslo, Norway. ${ }^{7} \mathrm{KG}$ Jebsen Center for B cell malignancies, Faculty of Medicine, University of Oslo, Oslo, Norway. ${ }^{8}$ Department of Medical Sciences, Haematology, Uppsala University, Uppsala, Sweden. ${ }^{9}$ Novo Nordisk Foundation Center for Stem Cell Biology, DanStem, Faculty of Health and Medical Sciences, University of Copenhagen, Copenhagen, Denmark. ${ }^{10}$ Department of Hematology, Rigshospitalet/National Univ. Hospital, University of Copenhagen, Copenhagen, Denmark "Wellcome Sanger Institute, Cambridge, United Kingdom. ${ }^{12}$ Oxcia AB, Stockholm, Sweden.

Note: Supplementary data for this article are available at Cancer Research Online (http://cancerres.aacrjournals.org/) are often responsible for AML progression. TH1579 killed AML cells by causing mitotic arrest, elevating intracellular ROS levels, and enhancing oxidative DNA damage. TH1579 showed a significant therapeutic window, was well tolerated in animals, and could be combined with standard-of-care treatments to further improve efficacy. TH1579 significantly improved survival in two different AML disease models in vivo. In conclusion, the preclinical data presented here support that TH1579 is a promising novel anticancer agent for AML, providing a rationale to investigate the clinical usefulness of TH1579 in AML in an ongoing clinical phase I trial.

Significance: The MTH1 inhibitor TH1579 is a potential novel AML treatment, targeting both blasts and the pivotal leukemic stem cells while sparing normal bone marrow cells.

successful treatment, the clonal expansion within the bone marrow (BM) and blood leads to BM failure and ultimately death. The AML blasts can often be eliminated with conventional chemotherapy (cytarabine/anthracycline), thereby achieving remission. However, LSCs are largely resistant to chemotherapy and consequently many patients will ultimately relapse, accounting for the leading cause of death in AML (5). Thus, identifying therapies that can eradicate LSCs is pivotal to achieve a durable clinical response.

There is emerging evidence that AML, like many other cancers, exhibits high levels of reactive oxygen species (ROS; ref. 6). Under

Current address for J.M. Calderón-Montaño: Department of Pharmacology, Faculty of Pharmacy, University of Seville, Seville, Spain; current address for V. Tsuber, Department of Medical Chemistry, Ukrainian Medical Stomatological Academy, Poltava, Ukraine; and current address for Y. Heshmati: Cancer and Blood Disorders Center, Dana Farber Cancer Institute and Boston Children's Hospital, Harvard Medical School, Boston, Massachusetts.

K. Sanjiv, J.M. Calderón-Montaño contributed as co-first authors of this article.

Corresponding Author: Ulrika Warpman Berglund, Department of Oncology Pathology, Karolinska Institute, Tomtebodavägen 23A, Stockholm 17121, Sweden or Oxcia AB, Norrbackagatan 70C, SE-113 34 Stockholm, Sweden. Phone: 46-73-2709605; E-mail: ulrika.warpmanberglund@scilifelab.se or ulrika.warpmanberglund@oxcia.com

Cancer Res 2021;81:5733-44

doi: 10.1158/0008-5472.CAN-21-0061

This open access article is distributed under Creative Commons AttributionNonCommercial-NoDerivatives License 4.0 International (CC BY-NC-ND).

(C)2021 The Authors; Published by the American Association for Cancer Research 
normal conditions, low levels of ROS are important for selfrenewal, regeneration, and proliferation of hematopoietic stem cells (7). However, high levels of ROS are suggested to target the differentiation of leukemic blasts and LSCs, and thus promote leukemogenesis $(6,8,9)$. Particularly the mutant receptor kinases FLT3, cKIT, RAS, and IDH1/2 seem to drive intracellular ROS production in AML (for review, see ref. 8). Furthermore, a correlation between high ROS and poor prognosis in FLT3/IDT AML subtype has been reported (10). Excessively elevated ROS levels can cause fatal oxidative damage to DNA and proteins, leading to apoptosis and become lethal for the cell (11). Therefore, cancer cells must develop antioxidant defenses to keep ROS at high, but tolerable, levels.

It was previously hypothesized that proteins, such as MTH1 (human MutT homolog 1, NUDT1), that prevent the conversion of high ROS levels into DNA damage, could be suitable molecular targets to selectively cause DNA damage in cancer cell (12-19). MTH1 hydrolyses oxidized nucleotides, such as 8-oxo-dGTP and 2-OH-dATP, in the dNTP pool into their corresponding monophosphates. An excess of 8-oxo-dGTP incorporation into DNA causes $\mathrm{G}: \mathrm{C} \rightarrow \mathrm{T}: \mathrm{A}$ transversions, DNA damage responses, and cell senescence (20). ROS accumulates in mitotically arrested cells $(21,22)$. MTH1 protein also has roles in mitosis, binding tubulin, and promoting microtubule polymerization (23), but these roles are largely uncharacterized to date. MTH1 is dependent on the redox balance in the cell for activity and ROS levels in the cell dictate the responses of the MTH1 inhibitors (MTH1i) TH588 and TH1579 $(24,25)$. Interestingly, MTH1 is overexpressed in various cancer forms, for example, hematologic cancers (www. proteinatlas.org; ref. 26), breast cancer (27), colon, lung, and pancreatic cancers (28), suggesting that the cancer cells use this pathway to survive their dysregulated redox balance. We have previously identified first-in-class MTH1i, showing anticancer properties in solid cancers $(12,13,23,25,29-32)$. These cytotoxic MTH1i have a dual action; (i) cause a mitotic arrest by disturbing microtubule polymerization, which in the case of TH588 and TH1579 is likely mediated also by an MTH1-independent direct inhibition of tubulin polymerization $(23,33)$, and induce ROS and 8-oxodGTP production, and (ii) elevate oxidized nucleotide incorporation into DNA by MTH1 inhibition $(23,34)$. MTH1 inhibitors that do not arrest cells in mitosis fail to show toxicity in monotherapy (23). A complete understanding of the complex role of MTH1 and detailed mechanism of action of TH1579 is still missing.

The clinical candidate MTH1i TH1579 (karonudib), is presently undergoing two clinical phase I studies investigating safety and tolerability in patients with any type of advanced solid tumor malignancies (https://clinicaltrials.gov/, MASTIFF, NCT03036228) and in relapsed/refractory hematologic malignancies (https://clinicaltrials. gov/, MAATEO, NCT04077307).

Here, we show preclinical data from AML cancer cell lines (CCL), AML (blast and cells enriched for LSCs) patient BM samples, and two AML disease models, supporting the beneficial effect of TH1579 therapy in AML.

\section{Materials and Methods \\ Compounds}

TH588, TH1902, TH1939, TH1579, and AZ19 were prepared according to published methods (ref. 12; WO2015187088; ref. 35). Paclitaxel, vincristine, cytarabine, doxorubicin, and venetoclax were purchased from Sigma-Aldrich.

\section{Sanger screen}

Three MTH1 inhibitors, TH588, and two more optimized analogs, TH1902 and TH1939, were tested at Sanger Institute for cell viability in 715 CCLs. The cell assay is described in Iorio and colleagues (36). Correlations were performed using publicly available AUC values from Cancer Therapeutic Response Portal, Broad Institute, of 433 overlapping CCLs response to 481 FDA-approved drugs, clinical candidates and small molecules (37), and AUC values from MTH1i in same CCLs. Pearson $r$ was normalized across dataset by Fisher ztransformation to account for differences in number of complete observations for each pairwise combination.

\section{Cell lines culture}

HL60 (AML), K562 (chronic myeloid leukemia), Kasumi (AML), KG1a (AML), MV4-11 (AML), THP-1 (AML), A3 (T-cell acute lymphoblastic leukemia, T-ALL), CCRF-CEM (T-ALL), Jurkat (TALL), Molt4 (T-ALL), KBM-3 (AML), PL-21 (AML), NB4 (acute promyelocytic leukemia, APL), SU-DHL-5 (diffuse large B-cell lymphoma, DLBCL) were purchased from ATCC. All cells except KBM3 were maintained in RPMI1640 medium with GlutaMax. Media were supplemented with $10 \%$ heat-inactivated FBS, $100 \mathrm{U} / \mathrm{mL}$ penicillin, and $100 \mu \mathrm{g} / \mathrm{mL}$ streptomycin. KBM3 cells were cultured in Iscove's Modified Dulbecco's Medium with GlutaMax with 15\% heatinactivated FBS supplemented with $2 \%$ L-glutamin. Cells were maintained at $37^{\circ} \mathrm{C}, 5 \% \mathrm{CO}_{2}$ in a humid incubator, passaged a maximum of 25 times, checked for Mycoplasma contamination (MycoAlert Mycoplasma Detecton Kit, Lonza) every other month.

\section{Establishing of doxocycline-induced short hairpin RNA MTH1 HL60 cells}

HL60 short hairpin (shRNA) NT, MTH1\#2, MTH1\#3 cells were obtained as described in ref. 23.

NT shRNA: $5^{\prime}$-GGAACTAGCATACGTAAGTAA- ${ }^{\prime}$. MTH1 sh\#2 shRNA: $5^{\prime}$-CGAGTTCTCCTGGGCATGAAA- ${ }^{\prime}$. MTH1 sh\#3 shRNA: 5'-CGACGACAGCTACTGGTTT-3'.

\section{Viability assay}

Cell viability assay using resazurin was performed as described in ref. 12. Each experiment was performed in triplicates. Curves were fitted using GraphPad Prism and $\mathrm{IC}_{50}$ values were determined.

$\mathrm{N}$-acetyl-L-cysteine (NAC) experiment: 5,000 cells of different leukemic cell lines were seeded into 96 cells well plate with or without $2.5 \mathrm{mmol} / \mathrm{L}$ of (NAC, Sigma A9165-25G) followed by addition of different concentration of TH1579 using drug dispensing machine (D300e TECAN). After 72 hours of incubation period, resazurin was added to measure the viability of the cells using HIDEX plate reader.

\section{ROS experiment}

A total of 300,000 cells of different leukemic cell lines in 6-well plate were treated with TH1579 for 18 hours. Cells were resuspended in serum and antibiotic-free media and stained using ROS indicator CMH2DCF (Life Technologies, C8627) for 30 minutes and analyzed using FACS as per the manufacturer's protocol.

\section{Dead cell analysis by flow cytometry}

All experiments were carried out using a Navios flow cytometer from Beckman Coulter. Cells $\left(4-20 \times 10^{4} / \mathrm{mL}\right)$ were plated in 12-well plate or T-25 flasks in the presence or absence of MTH1i. The cells were recollected at the indicated timepoint (24, 72, or 120 hours); spun down for 5 minutes at $500 \mathrm{G}, 4^{\circ} \mathrm{C}$; washed once in cold PBS with $5 \%$ FBS; and fixed by freezing cells in 70\% ethanol; washed twice in cold PBS with 5\% FBS; resuspended in FACS buffer [ $20 \mu \mathrm{g} / \mathrm{mL}$ RNAse A, 
$0.1 \%$ Triton $\mathrm{X}-100$, and $50 \mu \mathrm{g} / \mathrm{mL}$ propidium iodide (PI) in PBS]. In the case of shRNA HL60 cells, the FACS buffer was $20 \mu \mathrm{g} / \mathrm{mL}$ RNAse A, $0.1 \%$ Tween- 20 and $10 \mu \mathrm{g} / \mathrm{mL}$ hoechst \#33342 in PBS. After 1 hour of dark incubation at $4{ }^{\circ} \mathrm{C}$, the samples were analyzed on flow cytometer. Cells below to the $G_{1}$ population peak were scored as dead cells.

\section{Western blot analysis}

Western blot analysis was performed as described previously (23). Following antibodies were used: rabbit anti-53BP1 (A300-272A, Bethyl Laboratories), mouse anti beta-Actin (ab6276, Abcam), rabbit anti-cyclin B1 (sc-594, Santa Cruz Biotechnology), rabbit antiGAPDH (sc-25778, Santa Cruz Biotechnology), mouse anti-H2AX phospho S139 (05-636, Millipore), mouse anti-Histone H3 phosphoS10 (pH3; ab14955, Abcam), rabbit anti-pH3 (ab5176, Abcam), goat anti-MAD2 (sc-6329, Santa Cruz Biotechnology), rabbit anti-MTH1 (NB100-109, Novus Biologicals), and rabbit anti-cleaved PARP (\#9541, Cell Signaling Technology). Secondary antibodies used: goat anti-mouse IgG Alexa Fluor 488 (A11029, Life Technologies), donkey anti-rabbit IgG Alexa Fluor 555 (A31572, Life Technologies), donkey anti-goat IgG IRDye 800CW (926-32214, LI-COR), donkey antimouse IgG IRDye $800 \mathrm{CW}$ (925-32212, LI-COR), donkey antirabbit IRDye 680RD (925-68073, LI-COR), and goat anti-rabbit IgG IRDye 800CW (926-32211, LI-COR).

\section{Immunofluorescence}

After treatment or shRNA induction, approximately 1 million cells/samples were recollected for quantitative immunofluorescence analysis of $\mathrm{pH} 3$ or colocalization of nuclear $\gamma \mathrm{H} 2 \mathrm{AX}$ and 53BP1 foci. Immunofluorescence experiments were performed as described previously (38).

\section{Modified comet assay}

A total of 300,000 HL60 cells were seeded in 6-well plates. Next day cells were treated with DMSO or TH1579 for 24 hours. Modified comet assay was performed as described previously (12).

\section{Cell culture and colony-forming assay of human primary AML 8227 and human BM}

The human AML 8227 is an aggressive, relapsed leukemia with mutations in p53, RUNX1, and FLT3-ITD and constitutes approximately $4 \%-8 \%$ of functional enriched $\left(\mathrm{CD} 34^{+} \mathrm{CD} 38^{-}\right)$LSCs. AML 8227 cells were cultured $(400,000$ cells $/ \mathrm{mL})$ in $1 \mathrm{~mL}$ Stemspan medium (Stem Cell Technologies) containing growth factors (IL3, $10 \mathrm{ng} / \mathrm{mL}$; SCF, $50 \mathrm{ng} / \mathrm{mL}$; IL6, $10 \mathrm{ng} / \mathrm{mL}$; FLT3L, $50 \mathrm{ng} / \mathrm{mL}$; GCSF, $10 \mathrm{ng} / \mathrm{mL}$; and TPO, $25 \mathrm{ng} / \mathrm{mL}$ ) and Primo + (antifungal/antibacterial agent) and incubated at $37^{\circ} \mathrm{C}, 5 \% \mathrm{CO}_{2}, 20 \% \mathrm{O}_{2}$. Colonyforming assays: early-passage 8227 AML cells were suspended in H4434 semisolid media for human cells (Stem Cell Technologies, $\# 03444), 1 \%$ pen strep to obtain a final cell concentration of 20,000 cells $/ \mathrm{mL}$. Whole human BM cells were prepared in parallel $(10,000$ cells $/ \mathrm{mL})$. The cell suspension mix in methylcellulose $(3 \mathrm{~mL})$ was treated with TH1579 and doxorubicin, alone or in combination, thoroughly vortexed and incubated for 10 minutes at $37^{\circ} \mathrm{C}$. Subsequently, solutions were plated in duplicates of $1 \mathrm{~mL}$ on nontissue culture treated 6-well plates (Corning Life Sciences, \#351146). After incubation at $37^{\circ} \mathrm{C}, 5 \% \mathrm{CO}_{2}, 95 \%$ humidity for 10 days, colonies formed by clonogenic AML cells and clonogenic control BM cells (i.e., normal hematopoietic progenitor cells) were counted by inverted microscopy to assess the $\mathrm{IC}_{50}$ for single drugs and drug combinations.

\section{Coculture of AML blasts and leukemia stem cells and mouse stroma cells}

The coculture of primary AML blast and enriched LSCs and flow cytometric analysis has been described previously (see Supplementary Data for details; ref. 39). The cells were treated with TH1579 (400 or $800 \mathrm{nmol} / \mathrm{L}$ ) or DMSO and propagated on the stromal cells until the control DMSO-treated cells reached confluency (5-10 days). Cells were harvested, spun down, washed once in cold FACS buffer (PBS and $2 \% \mathrm{FBS}$ ) and incubated with following antibodies: CD56-PECy5, CD235a-PECy5, CD3-PECy5, CD19-PECy5, CD14-PECy5, CD11bPECy5, CD34-APC, CD38-PerCpCy5.5, CD45-Alexa Flour700 for 20 minutes. The CD45 antibody was used to distinguish the human cells from the mouse MS5 stromal cells and PI for viability. Lineage-negative cells $\left(\mathrm{Lin}^{-}\right)$were defined as negative for the following surface markers: CD56, CD235a, CD3, CD19, CD14, CD11b. The number of immunophenotypic leukemic LSCs was assessed by FACS (LSRFortessa flow cytometer, Becton Dickinson) analysis of $\mathrm{PI}^{-} \mathrm{Lin}^{-} \mathrm{CD} 45^{+} \mathrm{CD} 34^{+} \mathrm{CD} 38^{-}$cells.

\section{Functional precision medicine ex vivo screen}

BM biopsies were obtained from patients newly diagnosed with AML and were transferred within 24 hours to the lab for processing. Mononuclear cells in the BM aspirates were isolated using gradient centrifugation with Lymphoprep (Stemcell Technologies) at $400 \times g$. The mononuclear cells were used for ex vivo drug sensitivity and resistance testing as described previously (40). Quality control and drug sensitivity scoring (DSS) calculation (41) and data analysis was performed using Breeze (breeze.fimm.fi), Morpheus (https://software. broadinstitute.org/morpheus/), and Graphpad Prism.

Written informed consent from patients were obtained and the studies using human primary material were performed in accordance with the Declaration of Helsinki and approved by Institutional Review Boards (ethical approvals: Copenhagen, H-15004577 and Stockholm Dnr 2017/2085-31/2).

\section{Synergy calculations}

Synergy of TH1579 and other drug combinations was calculated utilizing the SynergyFinder web application 2.0, allowing for interactive analysis of multidrug combination data (https://synergyfinder. fimm.fi/synergy/2020041617234918296/). Synergy $(\delta$, ZIP) scores between $0-10$ was defined as additive and $>10$ synergistic (41).

\section{Disease models}

All animal experiments were approved and conducted as per the European directive, ethical guideline, and regulations of the Institutional Review Committee, that is, Regional Animal Ethical Committee Stockholm (approval Dnr: N89/14,7053-2018). Upon arrival to animal facility, animals were housed 3-5 mice/cage, acclimatized in the animal house for a week with ad lib food and water, with a 12-hour light cycle. Temperature and humidity set according to laboratory animal guidelines and regulations. TH1579 $(45 \mathrm{mg} / \mathrm{kg}, 90 \mathrm{mg} / \mathrm{kg}$, twice daily, per oral, p.o.) was formulated in a vehicle solution of DMSO, Tween 80 , Kolliphore EL (Sigma) and sterile water, cytarabine $(50 \mathrm{~m} / \mathrm{kg}$ every day, intraperitoneal, i.p.) was formulated in saline.

The HL60adp xenograft model was established by injecting HL60 luciferase expressing cells intravenous into NOD/SCID IL2R ${ }^{-1-}$ female mice (Charles River) as described previously (42). All image experiments were conducted on an IVIS spectrum preclinical in vivo imaging system (Perkin Elmer). Animals were randomized into treatment groups. Treatment initiated 1 week after cell injection. Animals were euthanized when human endpoint (predefined as 
$0.6 \mathrm{p}$ according to Karolinska Institute human endpoint guide) was reached.

For the THP-1 xenograft model, NOD-SCID mice, (female, 67 weeks old, breeding colony at Karolinska Institutet animal facility) were injected subcutaneous with $1 \times 10^{6} \mathrm{THP}-1$ cells together with Matrigel (1:1, BD Biosciences) in the right flank area. When tumor volume reached approximately $70-100 \mathrm{~mm}^{3}$, the mice were stratified into five different groups and treatment initiated. Tumor volume was measured by a digital calliper twice a week and calculated using the formula (length $\times$ width $^{2} \times 0,52$ ). Animals were euthanized when tumor reached $1,000 \mathrm{~mm}^{3}$ or the human endpoint was reached.

The group sizes were based on previous experience of MTH1i and disease model. The exclusion/inclusion criteria were predefined in ethical license as was the human endpoint and maximal tumor burden was set as $1,000 \mathrm{~mm}^{3}$. Body weight measured twice weekly, and the general status of the treated animals were checked daily. Survival plots and tumor volume growth graphs were drawn using Graphpad Prism software.

\section{Results}

\section{MTH1 inhibitors efficiently kill hematologic cancers}

To further understand the response of various cancers to our MTH1i, we performed a viability screen with three MTH1i (TH588, TH1902, and TH1939) at Sanger institute in 715 different CCLs, including 131 hematopoietic CCLs. The two more optimized compounds from the same chemical series, TH1902 and TH1939, were the most potent of the three drugs tested for all CCLs (Fig. 1A). A further analysis of hematopoietic CCLs showed that differences in sensitivity are probably related to properties of individual hematopoietic CCLs rather than dependent on the type of disease (Fig. 1B; Supplementary Table S1). We used the publicly available AUC values of 433 overlapping CCLs' response to $481 \mathrm{FDA}$-approved drugs, drugs under clinical evaluation and small-molecule probes (37) and correlated with the AUC values following treatment with MTH1i in the same CCLs. The analysis revealed that for each of the tested compounds, apart from correlations with the other MTH1i, the highest values of the Pearson $r$ are for correlations with inhibitors of polo-like kinase 1 (PLK1), microtubule, topoisomerase, and AURORA kinase (Fig. 1C). TH1902 correlates more strongly to topoisomerase inhibitors and TH1939 correlates more strongly to microtubule inhibitors in hematopoietic and lymphoid tissue (Fig. 1D).

In agreement with the three tested MTH1i, majority of the hematopoietic CCLs tested were sensitive to the best-in-class analog and clinical candidate drug TH1579 (karonudib; ref. 13), with two outliers: NB4 was the most susceptible and KBM3 the least susceptible hematopoietic CCL (Fig. 2A and B). In contrast to TH1579 treatment, KBM3 cells responded well to the microtubule inhibitors paclitaxel and vincristine (Fig. 2C; Supplementary Fig. S1A). We and others have previously shown that the oxidative environment of the cancer cell is important for the cytotoxicity of TH588 and TH1579 $(12,13,24,25,43)$. Here we found that NB4, the most sensitive hematopoietic CCL tested, also had the highest level of endogenous ROS (Fig. 2D). However, the resistant KBM3, did not show significantly lower endogenous baseline ROS compared with other TH1579-sensitive hematopoietic CCLs (Fig. 2D). The basal levels of MTH1 did not correlate to sensitivity in KBM3, NB4, HL60, and A3 CCLs (Fig. 2E), in line with previous findings (12). $\gamma \mathrm{H} 2 \mathrm{AX}$ was endogenously high in NB4 cells, while KBM3 showed endogenously low levels (Fig. 2E).

TH1579 did not induce any cell death in healthy human blood mononuclear cells (PBMC) at the concentrations used (Fig. 2F).

\section{TH1579 induces mitotic arrest and oxidized DNA damage, resulting in AML death}

TH588 cytotoxicity has been proposed to be independent of MTH1 and 8-oxodGTP $(35,44,45)$, but dependent of ROS $(43)$. We and others have previously shown that TH588 cytotoxicity is related to ROS, partly rescued by expression of 8-oxodGTPase MutT and disturbs mitotic progression and induces accumulation of genomic 8 -oxodG, contributing to cell killing $(12,13,24,34)$. In line with our previous findings, TH1579- and TH588-treatment caused HL60 cells to arrest in $\mathrm{G}_{2}-\mathrm{M}$-phase of the cell cycle and increased number of mitotically arrested cell (Fig. 3A-C; Supplementary Fig. S1B). TH1579 treatment elevated ROS levels (Fig. 3D) and increased incorporation of oxidized nucleotides such as 8-oxodG in DNA in HL60 cells (Fig. 3E; Supplementary Fig. S1C). TH1579 did not induce ROS in the resistant KBM3 cell, but significantly increased ROS in the TH1579-sensitive NB4 and A3 cells (Fig. 3F). Pretreatment with the ROS scavenger, NAC, showed a minor, but significant, rescue of TH1579-induced cytotoxicity at the higher concentrations in HL60 and A3 cells (Fig. 3G; Supplementary Fig. S1D-F). Confirming our previously observed effects in solid cancers $(12,13)$, TH1579 and TH588-treatment induced phospho-histone 3, reduced spindle assemble checkpoint MAD2, HL60 cells, increased $\gamma \mathrm{H} 2 \mathrm{AX}$, cleaved PARP, 53BP1 (Fig. 3H-I; Supplementary Fig. S2A-E) and increased number of dead cells (Fig. 3J; Supplementary Fig. S2F). TH1579 did not induce any DNA damage response in the resistant KBM3 cells (Fig. 3I), consisting with the TH1579 resistance.

Interestingly, by combing a non-cytotoxic MTH1i, AZ19 (35), with microtubule inhibitor paclitaxel, we could make the non-cytotoxic MTH1i cytotoxic and accumulate genomic 8-oxodG (Supplementary Fig. S3A-E), indicating the importance of the delayed mitotic progression in combination with genomic accumulation of oxidized nucleotides for overall effect of cytotoxic MTH1i.

\section{MTH1 plays a role in AML survival}

Because there has been a discussion of the role of MTH1 in cancer (46), we performed MTH1 shRNA knockdown in HL60 cells using a doxycycline-induced system and two different shRNA primers. MTH1 shRNA knockdown significantly slowed down cell proliferation (Supplementary Fig. S4A), enhanced number of dead and mitotically arrested cells (Supplementary Fig. S4B and C) and elevated cleaved PARP and $\gamma \mathrm{H} 2 \mathrm{AX}$ (Supplementary Fig. S4D-F), indicating apoptosis and DNA damage. Thus, these data suggest that MTH1 plays some role in AML proliferation and survival, however less pronounced compared with the drug treatments.

\section{TH1579 kills both primary AML blast and stem cells while sparing normal cells}

Because LSCs plays an important role in drug resistance, we were interested to evaluate the effect of TH1579 on primary AML blast and enriched LSCs. BM cells originating from 22 different patients were cocultured with mouse stroma cells keeping the immunophenotypic hierarchy of blasts and enriched LSCs. Using flow cytometric analysis, the MTH1i was shown to significantly prevent growth of 19 of 22 AML samples, compared with control (DMSO)treated patient samples (Supplementary Fig. S5). TH1579 significantly prevented cell growth of both the $\mathrm{CD} 45^{+}$AML blasts as well as the cells enriched for LSCs $\left(\mathrm{Lin}^{-} \mathrm{CD} 34^{+} \mathrm{CD} 38^{-}\right.$; Fig. $\mathbf{4 A}$ and $\mathbf{B}$; Supplementary Fig. S5 and S6). TH1579 was 4.5-fold more cytotoxic against human AML cells compared with human BM cells from healthy donors (Fig. 4C; Supplementary Fig. S7), indicating a therapeutic window. 
MTH1 Inhibitor TH1579 as a New Potential Therapy in AML

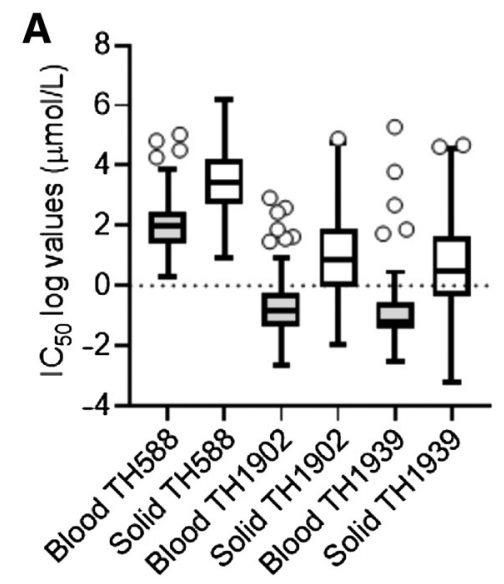

B
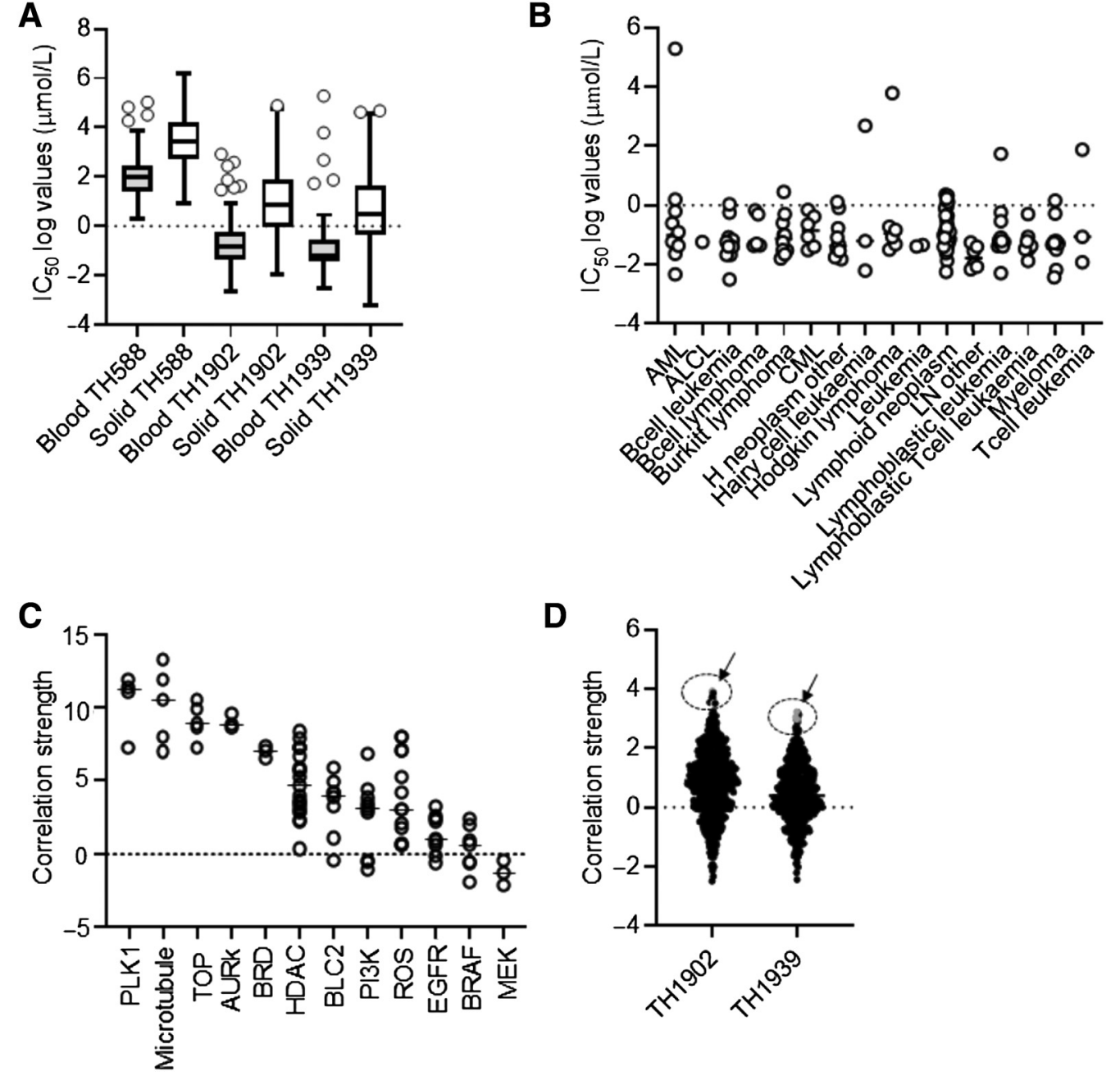

Figure 1.

Hematologic cancers sensitive to MTH1 inhibitors and show best correlation to mitotic arrest agent's response profile. A, Log IC 50 ( $\mu$ mol/L) values of TH588, TH1902, and TH1939 in 131 blood CCLs and 584 solid CCLs from a viability screen performed at Sanger Institute. B, Log IC 50 ( $\mu \mathrm{mol} / \mathrm{L}$ ) values of TH1939 in 131 blood cancer (same set as shown in A), separated on the basis of diagnosis. C, Correlation between AUCs to Cancer Therapeutics Response Portal, Broad Institute, AUC data of 481 small molecules in up to 433 overlapping cell lines in A. Pearson $r$ was normalized across the dataset by Fisher z-transformation to account for differences in number of complete observations for each pairwise combination. D, Correlation in CCLs from hematopoietic and lymphoid tissues as CCL Encyclopedia primary site, 72 CCLs total. TH1902 correlates more strongly to topoisomerase (circle, gray dots, similar to topotecan and etoposide) and TH1939 correlates more strongly to microtubule inhibitors (circle, gray dots, similar to isoevodiamine, parbendazole).

\section{TH1579 has a broad response profile in functional precision medicine ex vivo screen}

We have set up a functional precision medicine ex vivo cell viability screen assay to identify responders to novel and approved treatments using BM samples from patients with AML at diagnosis. BM samples from 27 patients with AML were treated with either vehicle, TH1579, the approved AML drugs cytarabine, venetoclax, doxorubicin, or microtubule inhibitors vincristine and paclitaxel as monotherapy. Figure 4D shows the DSS of the treatments in individual AML patient samples. The known AML genetic mutations for each patient are listed above the DSS scores. TH1579 showed a broad response in most patients with AML, similar to cytarabine and doxorubicin response pattern. No correlation between response and the common genetic mutations were observed.
TH1579 combined with venetoclax or doxorubicin may be beneficial in AML. Because TH1579 is presently investigated for safety and tolerability in a phase I trial in hematologic cancers, we wanted to identify the most effective combination treatments for future clinical development. Today the standard-of-care treatment for AML consists of chemotherapeutics, such as cytarabine (ARA-C) and anthracyclines, for example, doxorubicin. Venetoclax (BCL2 inhibitor) was recently FDA approved for treatment of AML in combination with azacytidine, decitabine and low-dose cytarabine. Microtubule inhibitors are not commonly used in AML, but as we identified microtubule inhibitors as a class of drugs that our MTH1i show similarities with (Fig. 1C and D), we included them as well. Thus, cytarabine, venetoclax, vincristine, paclitaxel, colchicine combinations with TH1579 were performed in HL60 cells (Fig. 4E and F; Supplementary Fig. S8A-H; Supplementary Table S2) and 
A

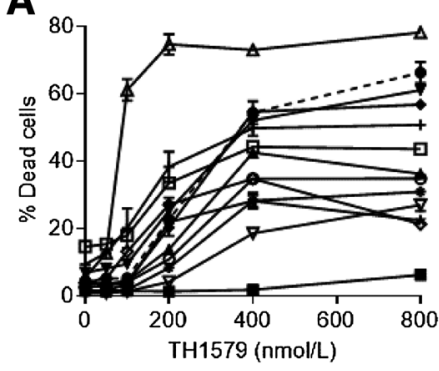

D

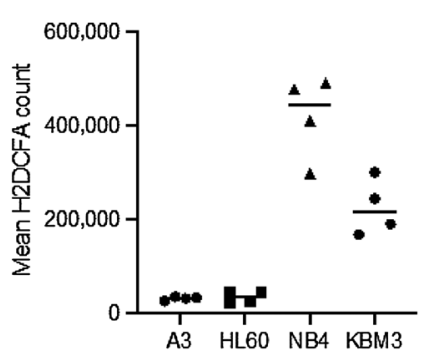

B
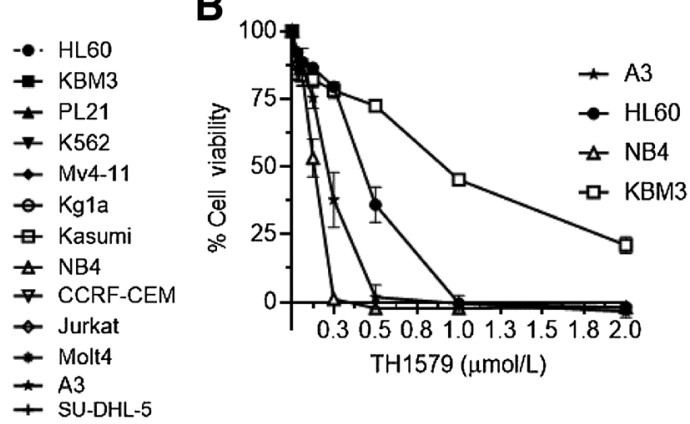

$\underset{\mathrm{pH} 3}{\text { E }}$

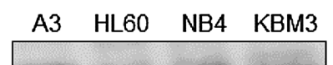

B-Acti

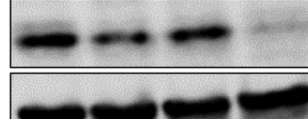

$17 \mathrm{KD}$

MTH1
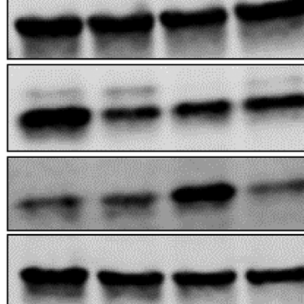

C

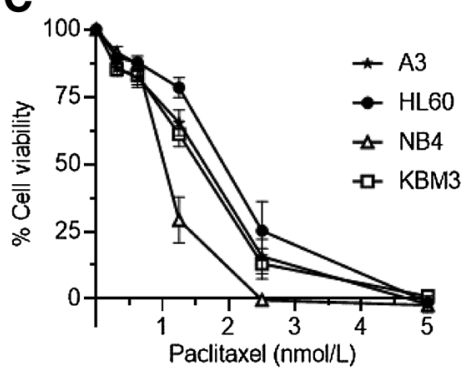

F

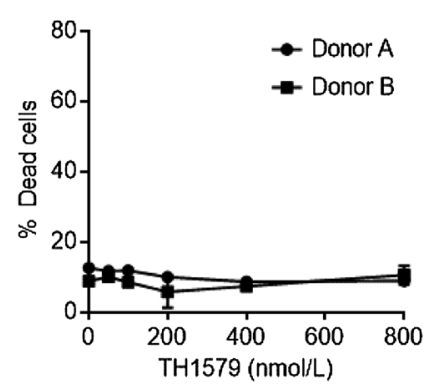

Figure 2.

Hematologic cancers sensitive to TH1579 treatment. A, TH1579 induces cell death in various hematological cancer cell lines (HL60, PL21, K562, Mv4-11, Kg1a, NB4, CCRF-CEM, Jurkat, Molt4, A3, SU-DHL-5, Kasumi, KBM3). KBM3 cells were resistant to TH1579 treatment. After 72 hours treatment, cells were stained with PI and analyzed by FACS. The percentage of dead cells was determined on the basis of the subG population. Data shown as mean \pm SEM of two to four independent experiments. B, TH1579 treatment reduces cell viability of leukemia CCLs. IC 50 values: $132 \pm 6 \mathrm{nmol} / \mathrm{L}$ (NB4), $234 \pm 24 \mathrm{nmol} / \mathrm{L}$ (A3), $456 \pm 35 \mathrm{nmol} / \mathrm{L}$ (HL60), and 1365 $\pm 255 \mathrm{nmol} / \mathrm{L}$ (KBM3); mean $\pm \mathrm{SEM}, n=3-5$. C, Paclitaxel treatment reduces cell viability of leukemic CCLs. IC 50 values: $1.1 \pm 0.09 \mathrm{nmol} / \mathrm{L}(\mathrm{NB} 4), 1.7 \pm 0.14$ $\mathrm{nmol} / \mathrm{L}$ (A3), $2.1 \pm 0.22 \mathrm{nmol} / \mathrm{L}$ (HL60), and $1.5 \pm 0.02 \mathrm{nmol} / \mathrm{L}$ (KBM3); mean $\pm \mathrm{SEM}, n=3-5$. Note that the KBM3 cells are as sensitive as the other CCLs for the treatment. For $\mathbf{B}$ and $\mathbf{C}$, cells were treated with drug for 72 hours and cell viability measured using resazurin assay. Data shown mean \pm SEM of three to five independent experiments. D, Endogenous intracellular ROS level in leukemic CCLs, untreated, measured by H2DCFA flow cytometry method. Mean \pm $\mathrm{SEM}, n=4$ but from two different days. E, One typical example of Western blot analysis on endogenous levels of phosphorylated histone 3 (s10H3), MTH1, $\gamma \mathrm{H} 2 \mathrm{AX}$ ( $\beta$-actin intrinsic control) in untreated CCLs. F, Treatment for 96 hours with TH1579 does not induce cell death in normal PBMC from two donors. Data shown as mean \pm SEM of duplicates from two individual donors.

cytarabine/TH1579 and venetoclax/TH159 combination performed in eight AML primary samples (Supplementary Fig. S9A and B). Cytarabine and microtubule inhibitor combination with TH1579 were further investigated in THP-1 cells (Supplementary Table S2). Synergy score and most synergetic area score were calculated using the ZIP method. Cytarabine/TH1579 showed the lowest synergy score and vincristine/TH1579 and venetoclax/ TH1579 the highest synergy (Fig. 4E and F; Supplementary Fig. S8A-S8H, S9A, S9B, S10A-C; Supplementary Table S2).

Interestingly, combinatorial treatment with TH1579 and doxorubicin showed significant synergistic therapeutic inhibition of human AML cells (ZIP synergy score: 16.9) but not normal human BM cells, ZIP synergy score: -0.862 (Fig. 4G and $\mathbf{H}$ ).

\section{TH1579 reduces tumor growth and increases survival in AML} disease models

TH1579 responds well in both HL60 and THP-1 cells (Fig. 2A; Supplementary Fig. S11A) and both human AML cell lines were grafted in mice to investigate the effect of TH1579 in AML disease models. Oral treatment with TH1579 $(45 \mathrm{mg} / \mathrm{kg}$ twice daily and $90 \mathrm{mg} / \mathrm{kg}$ twice daily, three times a week) inhibited the AML progression in NOD/SCID IL2 $\mathrm{R}^{-1-}$ female mice preinjected intravenously with human HL60Adp luciferase expressing cells and significantly increased the overall survival of treated animals (Fig. 5A-C; Supplementary Video).

TH1579 showed significantly better tumor growth inhibition and increased survival than one of the standard-of-care treatments for AML, cytarabine (ARA-C), in NOD/SCID mice grafted subcutaneously with THP-1 (Fig. 5D and E). The combination treatment of TH1579 and cytarabine did not show any additional efficacy (Fig. 5D and E). TH1579 was well tolerated and no effect on body weight was observed (Supplementary Fig. S11B). During the 6-week treatment period, all mice in the combination and the low-dose TH1579 groups had tumor volume (TV) that reached maximum survival criterion of $1,000 \mathrm{~mm}^{3}$. In the high-dose TH1579 group, only 1 of 6 mice developed a TV of $1,000 \mathrm{~mm}^{3}$. To assess resistance, we restarted another cycle of TH1579 treatment in 4 mice whose tumor went back into remission and grew over $100 \mathrm{~mm}^{3}$; one of these mice had skin sore and was terminated earlier. After 6 weeks of remission treatment with TH1579, their TV remained at approximately the same as the pretherapeutic volume. The efficacy of TH1579 in suppressing tumor growth during this second cycle of 6-week treatment showed that the mice had not developed resistance to the drug. Three of 4 mice responded well to TH1579 treatment. At the end of the study, which was 3 weeks after the cessation of the second treatment cycle, 2 mice had TVs approaching $1,000 \mathrm{~mm}^{3}$, and the 1 mouse whose restarted 
A

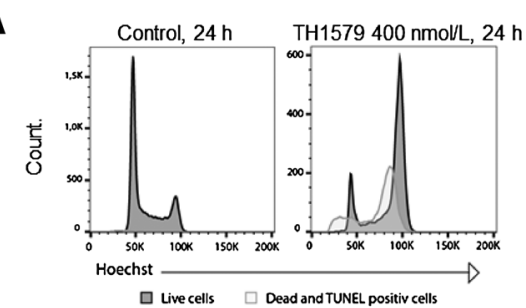

D

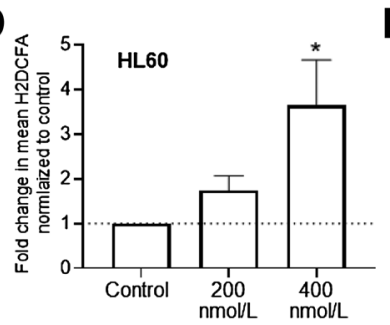

H

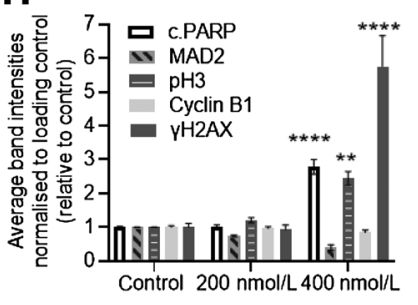

E

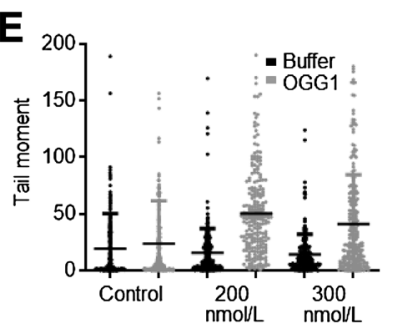

I

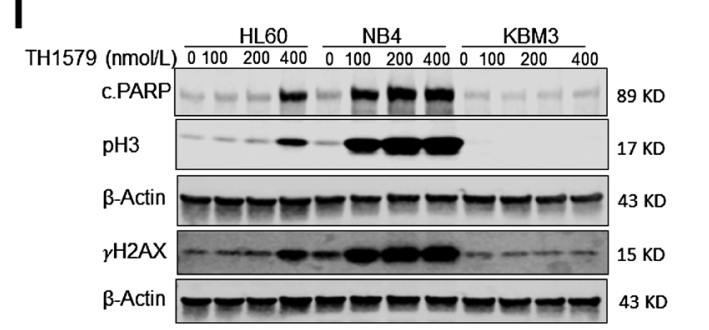

B Live cells

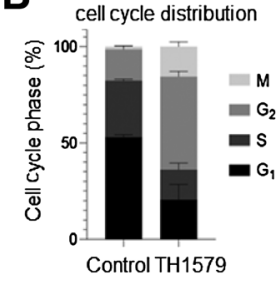

$\mathbf{F}$

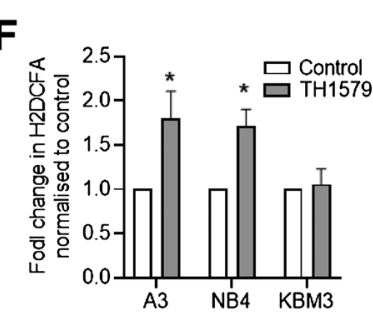

$\mathrm{J}$
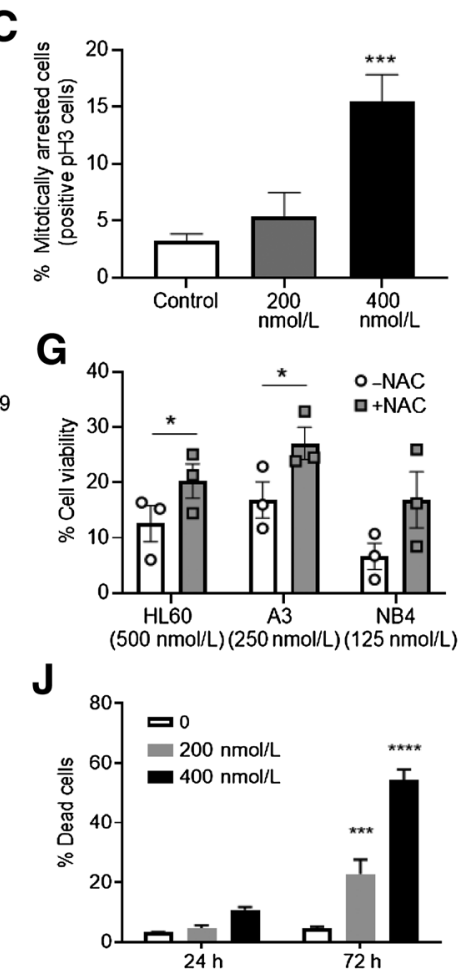

Figure 3.

TH1579 kills AML cells by causing $\mathrm{G}_{2}-\mathrm{M}$ arrest, increases ROS, genomic 8oxodG, and DNA damage. A, A total of 24 hours treatment of TH1579 induced cell death mostly from $\mathrm{G}_{2}-\mathrm{M}$. $n=3$. B, TH1579 causes $\mathrm{G}_{2}-$ M arrest in $\mathrm{HL} 60$ cells. Mean $\pm \mathrm{SEM}, n=3$. C, TH1579 increases number of mitotically arrested cells. After 24 hours treatment, cells were stained with Histone H3-pS10 antibodies and DAPI. H3pS10-positive cells with chromatin condensation were scored as mitotic cells. Data shown as percentage of total cells. Mean \pm SEM from two to four independent experiments. ${ }^{* * *}, P<0.001$, one-way ANOVA, Tukey multiple comparison. D, TH1579 induces ROS levels in HL60 cells. ROS was measured using ROS indicator CM-H2DCF. After 18 hours of treatment, it was analyzed using FACS and normalized to control (DMSO)-treated cells. Mean \pm SEM from four independent experiments. * $P<0.05$, one-way ANOVA, Tukey multiple comparison. E, Quantitative data of modified comet assay from HL60 cells treated with MTH1 inhibitor for 24 hours showing an increase in tail moment after addition of OGG1 enzyme in DNA of HL60 cells. Data shown as mean \pm SEM from $n=2$ independent experiments. F, TH1579 (400 nmol/L, 18 hours treatment) significantly elevates ROS in NB4 and A3 cells, while no ROS induction was observed in the resistant KBM3 cells. Data normalized to control (DMSO)-treated cells. Mean \pm SEM from four independent experiments. ${ }^{*}, P<0.05$ compared with control-treated cells in NB4, A3, KBM3, respectively. Student $t$ test. G, NAC treatment partly rescues TH1579-induced toxicity. HL60, NB4, and A3 cells treated with $2.5 \mathrm{mmol} / \mathrm{L} \mathrm{NAC}$ and TH1579 at concentrations as mentioned in the figure for 72 hours. Mean \pm SEM; $n=3$ independent experiments. *, $P<0.05$, Student $t$ test. (full curves in Supplementary Fig. 1D-F). H, Quantification of Western blot analysis from three independent treatment experiments following 24-hour TH1579 treatment in HL60 cells showing increased expression of DNA damage, mitotic, and apoptotic markers. Mean \pm SEM. ${ }^{* *}, P<0.01 ;{ }^{* * *}, P<0.0001$. Two-way ANOVA, Tukey multiple comparison (representative Western blot analysis in Supplementary Fig. S2A). I, A typical example of Western blot analysis following 18-hour TH1579 treatment in HL60, NB4, and KBM3 cells, showing elevated levels of DNA damage in the TH1579sensitive NB4 and HL60, but no DNA damage response in resistant KBM3 cells. J, Dose-dependent increase in percentage of dead cells measured by FACS analysis of the subG 1 population in $\mathrm{HL60}$ cells. Data shown as mean $\pm \mathrm{SEM}$ from three to four experiments.

treatment later was still under treatment and had TV of $119 \mathrm{~mm}^{3}$ (Fig. 5D).

\section{Discussion}

Here we provide preclinical support that TH1579, an optimized MTH1i and clinical candidate drug, shows efficacy as monotherapy, as well as in combination with standard of care, in AML. While disease control in preclinical models is profound, this may not necessarily translate into benefit over existing treatments in the clinic. There are however several interesting aspects that make TH1579 interesting. First, TH1579 is orally available and administered as tablets in ongoing clinical studies. Second, TH1579 shows a therapeutic index (Fig. 4C) and thus potential to be well tolerated. This is in contrast to many other treatments for AML that cause hospitalization, due to administration route, and severe adverse effects. This may for instance be beneficial to elderly patients with AML often deemed unfit for advance chemotherapy. Third, we show TH1579 treatment kills both AML bulk and the cell population enriched for LSCs. This is of importance because LSCs propagates AML by generation of partial differentiated leukemic blast cells forming the bulk of the disease (3) and have been suggested to play a key role in chemotherapy resistance and relapse (47). Mechanistically, TH1579 induces ROS (Fig. 3; refs. 23, 25) and may thus alter the redox status in LSCs, increasing the DNA damage and cell death. The phase I study (MAATEO, NCT04077307) is presently recruiting patients with hematologic malignancies (AML, ALL, DLBCL, Burkitt lymphoma, multiple myeloma or high-risk myelodysplastic syndome) to evaluate safety, tolerability, and efficacy of TH1579 and will likely provide further details on the prospect of TH1579 in treatment of AML.

The mechanism of action of MTH1i as well as the role of MTH1 as a target in cancer treatment is under debate (46). We could confirm a 

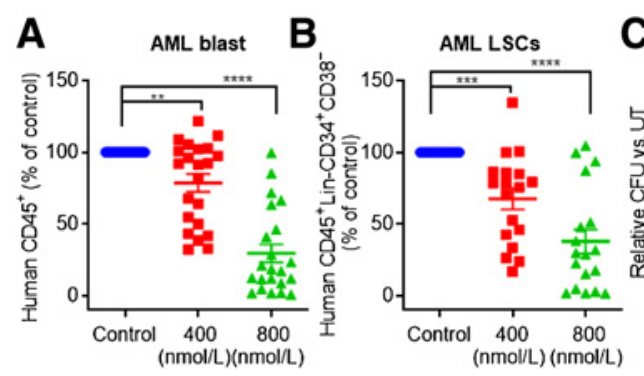

C
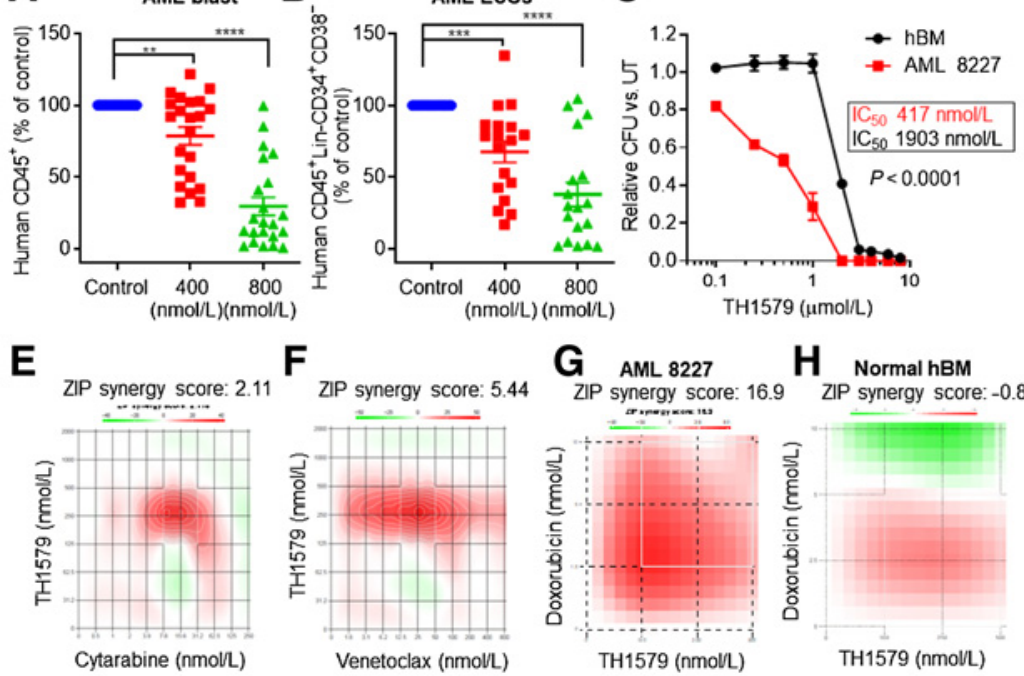

H Normal hBM

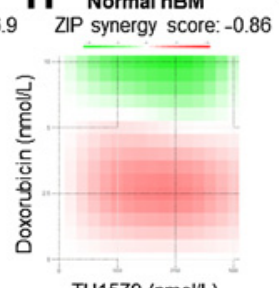

D

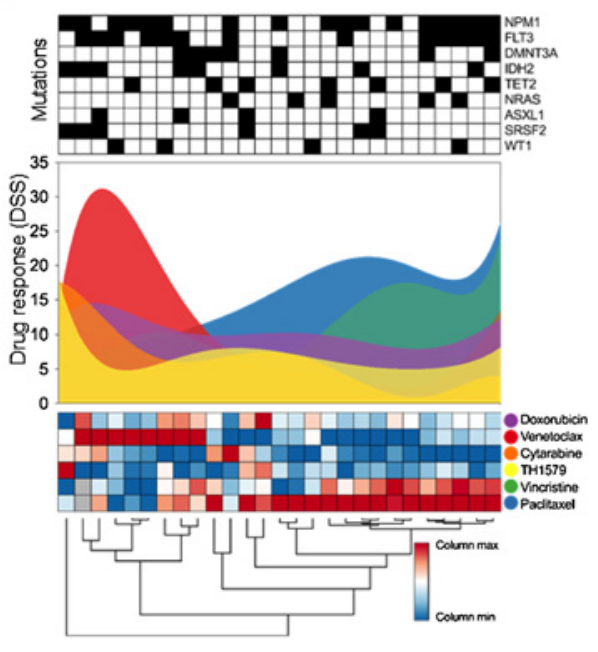

Figure 4 .

TH1579 kills AML blast and LSCs, shows a therapeutic window and has a similar profile as standard-of-care in functional precision medicine ex vivo screen and can improve SoC efficacy. A, Primary AML BM biopsies from 22 patients with AML were cocultured with mouse stroma cells and treated with TH1579 (400 and $800 \mathrm{nmol} / \mathrm{L}$ ) or DMSO control for 72 hours. Using FACS sorting for human CD45 ${ }^{+}$, the TH1579 effect on AML blasts cells was investigated. Data shown as percent change of control. Mean \pm SEM of 22 patients. Individual data shown in Supplementary Fig. $2 A . * *, P<0.01 ;{ }^{* * * *}, P<0.0001$, one-way ANOVA. B, Using FACS, sorting for human $\mathrm{CD}_{4} 5^{+} \mathrm{Lin}^{-} \mathrm{CD} 34^{+} \mathrm{CD} 38^{-}$, the TH1579 induced effect on AML cells enriched for LSCs were analyzed following 72 hours treatment with TH1579. Data shown as percent change of control. Mean \pm SEM of 22 patients. ${ }^{* * *}, P<0.001 ;{ }^{* * *}, P<0.0001$, one-way ANOVA Individual data shown in Supplementary Fig. $2 \mathrm{~B}$. C, TH1579 inhibits proliferation and survival of human AML 8227 cells at significantly lower doses compared with normal whole human bone marrow (hBM) cells, reflecting a substantial therapeutic window in favor of human AML cells (AML IC $50417.4 \mathrm{nmol} / \mathrm{L}$ vs. hBM $1903 \mathrm{nmol} / \mathrm{L}, P<0.0001$, ANOVA). Dose-response curves and IC 50 estimations were made using non-linear regression. Mean \pm SEM from duplicate samples. Cells were treated with TH1579 for 10 days. Results are presented relative to untreated cells (UT). D, Bottom, patient-specific relative DSS of TH1579, cytarabine, paclitaxel, vincristine, doxorubicin, and venetoclax, ordered by hierarchical clustering (Pearson). Middle, a line fit histogram using absolute DSS values. Top, mutations occurring in more than two patients across cohort are indicated for each patient in black. E, HL60 cells were treated with TH1579 and cytarabine for 72 hours. At the end of the incubation period, viability was measured using resazurin. Synergy plot was derived using ZIP method. Images represent one replicate performed in duplicate. Two independent experiments were performed. F, HL60 cells were treated with TH1579 and venetoclax for 72 hours. At the end of the incubation period, viability was measured using resazurin. Synergy plot was derived using ZIP method. Images represent one replicate performed in duplicate. Two independent experiments performed. G, Synergistic interaction between TH1579 and doxorubicin in AML patient BM biopsy. Synergy plot using ZIP analysis. H, Lack of synergy between TH1579 and doxorubicin in control human BM cells. Synergy plot using ZIP analysis on combination TH1579-doxorubicin.

role of MTH1 in AML by depleting MTH1 in HL60 cells showing reduced survival. However, the observed effects following MTH1 depletion was mild and not as pronounced as with the MTH1i, which may partly be explained by the incomplete level of MTH1 knockdown, but also by the additional mitotic effect of TH1579 as it directly destabilizes microtubule polymerization (23). It is unclear how much of the toxic effect of TH1579 is mediated through targeting MTH1 and through direct effect on tubulin. In our original article, we reported differential sensitivity in CCLs to MTH1 knockdown, some being highly sensitive while others not sensitive at all (12). It is likely that the contribution of MTH1-mediated toxicity is dependent on the degree of dependency on MTH1 in the particular cell line. Hence, there is unlikely a general answer to the degree of MTH1 contribution to cell toxic effects. More insights into the biology of MTH1 is needed as well as better understanding of the TH1579 compound. In any case, we observe a correlation of the MTH1i response profile in the larger CCLs screen with other mitotic inhibitors such as PLK1, microtubule, topoisomerase and AURORA kinase inhibitors, indicating that the disturbed mitotic progression by MTH1i is important for the anticancer effect. This is further supported by our finding that a noncytotoxic MTH1i, AZ19 (35), can become cytotoxic and accumulate genomic 8-oxodG when combined with the mitotic inhibitor, pacli- taxel (Supplementary Fig. S3). However, the AML cell line KBM3 showed resistance to TH1579 (Fig. 2) but not to microtubule inhibitors paclitaxel and vincristine (Fig. 2; Supplementary Fig. S1A) and the response profile of TH1579 in functional precision medicine ex vivo screen did not resemble microtubule inhibitors, rather doxorubicin and cytarabine, demonstrating that TH1579 has likely a unique mechanism of action. Also, 8-oxodG incorporation has previously been shown to be cytotoxic and affect cell survival. For instance, in Rudd and colleagues (34), we show that replacement of one of the main DNA polymerases in human cells, DNA polymerase delta, with an errorprone variant allows increased 8-oxodG accumulation into DNA following treatment with the MTH1i TH588. The resulting elevated genomic 8-oxodG correlated with increased cytotoxicity of TH588. Interestingly, it has been shown that ROS accumulate throughout cell cycle, peaking in mitosis and accordingly induced following prolonged mitotic arrest $(21,22)$. TH1579 causes a prolonged mitotic arrest (Fig. 3) by directly disturbing tubulin polymerization and through disruption of binding between tubulin and MTH1 (23), increases ROS level (Fig. 3D-F) and likely causing increased 8-oxodGTP levels in mitosis (34), and by inhibiting the 8-oxodGTPase activity 8-oxodG is accumulated in DNA (Fig. 3E) and subsequent DNA damage (Fig. 3) and death 

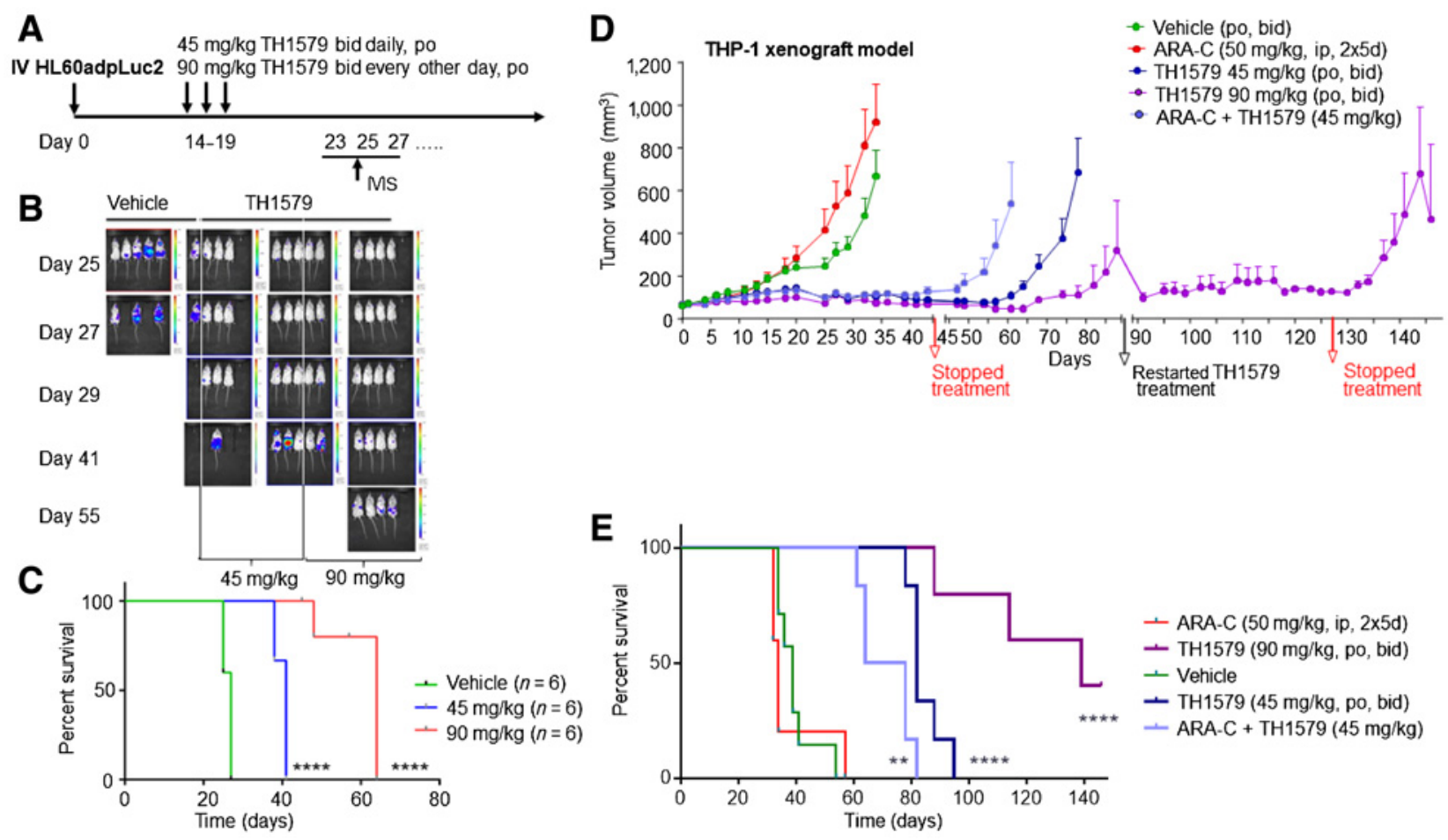

Figure 5.

TH1579 significantly increases survival in two different AML disease models. A, Treatment schedule in HL60adp AML disease model. B, TH1579 (45 mg/kg orally twice daily and $90 \mathrm{mg} / \mathrm{kg}$ orally twice daily every second day) significantly hindered the disease development compared with vehicle-treated animals. IVIS images up to 55 days after HL60adp injection. Luciferase was used to detect tumor cells. Blue, low signal; red, high signal. $N=6$ animals/treatment group. C, TH1579 treatment significantly prolonged survival in HL60adp iv disease model. D, Effect on tumor growth in THP-1 disease model following TH1579, cytarabine (ARA-C), or combination TH1579-cytarabine (ARA-C) treatment versus vehicle-treated animals. Data shown as mean \pm SEM of $n=5-6$ animals per group. During the 6-week treatment cessation period, all mice in the combination and the low-dose TH1579 groups had tumor volume that reached maximum survival criterion of 1,000 $\mathrm{mm}^{3}$; in the high-dose TH1579 group, only 1 of 6 mice developed tumor to $1,000 \mathrm{~mm}^{3}$. To assess resistance, another treatment cycle of TH1579 was initiated in four mice whose tumor went back into remission and grew over $100 \mathrm{~mm}^{3}$. At the end of the study, which was 3 weeks after the cessation of the second treatment cycle, two mice had tumor volumes approaching $1,000 \mathrm{~mm}^{3}$, and the one mouse whose restarted treatment later was still under treatment and had tumor volume of $119 \mathrm{~mm}^{3}$ when the study was terminated. E, Survival curve on data from $\mathbf{D}$. Animals were euthanized when tumor volume reached $1,000 \mathrm{~mm}^{3} .{ }^{* *}, P<0.01 ;{ }^{* * * *}, P<0.0001$, Mantel-Cox analysis survival curve.

(Fig. 3). Furthermore, additive/synergistic effects were observed when combining TH1579 with microtubule inhibitors, indicating differential mechanisms of action of the compounds (Supplementary Fig. S8). PLK1, microtubule, and AURORA kinase inhibitors have been investigated in clinical trials in patients with AML with poor clinical activity as single agents, but they offer potential therapeutic window when combined with low dose of cytarabine causing chromatin remodeling and DNA damage (48). Thus, the dual mechanism of action of TH1579, that is, the prolonged mitotic arrest and the generation of DNA damage by 8-oxodG incorporation into DNA, may be of therapeutic advantage in AML.

Here we demonstrate a broad TH1579 susceptibility of various hematologic and AML cell lines and primary AML BM samples. However, we observed some variability in responses to the TH1579 treatment, which could not be correlated to any genetically altered subtype of AML, nor to the level of endogenous ROS or MTH1. It is therefore tempting to speculate that the lack of response may be due to lack of induction of prolonged mitosis via microtubule disturbances. Clearly additional studies are needed to fully understand the mechanism of action of TH1579 and identify response biomarkers to help stratify patients with AML for TH1579 therapy.
The current therapy for newly diagnosed patients includes cytarabine and anthracycline (49). Recently, FDA granted accelerated approval of venetoclax, in combination with azacitidin or decitabine or with low-dose cytarabine for treatment of newly diagnosed elderly/ unfit patients with AML. Combining cytarabine and anthracycline enhances the DNA damage and inhibits the DNA repair thereby explaining the successful combination. Similarly, we hypothesized that by combining TH1579, which increases DNA damage and causes a prolonged mitotic arrest, with either cytarabine or an anthracycline, DNA damage would be further enhanced, resulting in an additive/ synergistic cytotoxic effect. Particularly the TH1579/doxorubicin combination showed strong synergy in human primary AML samples, explained by increased ROS levels and DNA damage (Centio and colleagues, personal communication). Further studies to fully understand the underlying mechanisms of the various beneficial combinations are needed and outside the scope of the work presented here. Thus, TH1579 treatment has potential to not only work as a monotherapy but also further improve efficacy of standard-of-care therapies in AML.

In conclusion, the preclinical data presented here support that TH1579 is a promising novel anticancer agent for AML and provide a rational to investigate the clinical usefulness of TH1579 (karonudib) in AML in the ongoing clinical phase I trial. 


\section{Authors' Disclosures}

K. Sanjiv reports grants from Radiumhemmets Forskningsfond (191282, U. Warpman Berglund), Swedish Foundation for Strategic Research (RB13-0224, U. Warpman Berglund), Vinnova (2015-04755, T. Helleday), Torsten and Ragnar Söderberg Foundation (T. Helleday), The Swedish Cancer Society (CAN2018/0658), The Swedish Research Council (2015-00162, 2017-06095), European Research Council (TAROX program, ERC-695376, T. Helleday), and The Swedish Childhood Cancer Fund, (PR2018-0095, T. Helleday) during the conduct of the study; other support from Oxia $\mathrm{AB}$ outside the submitted work. J.M. Calderón-Montaño reports grants from Radiumhemmets Forskningsfond, Swedish Foundation for Strategic Research, Vinnova, Torsten and Ragnar Söderberg Foundation, The Swedish Cancer Society, The Swedish Research Council, European Research Council, and The Swedish Childhood Cancer Fund during the conduct of the study; other support from Oxcia $\mathrm{AB}$ outside the submitted work. T.M. Pham reports grants from Radiumhemmets Forskningsfond, Swedish Foundation for Strategic Research, Vinnova, Torsten and Ragnar Sderberg Foundation, The Swedish Cancer Society, The Swedish Research Council, European Research Council, and The Swedish Childhood Cancer Fund during the conduct of the study; non-financial support and other support from Oxcia AB outside the submitted work. I. Almlöf reports grants from Radiumhemmets Forskningsfond, Swedish Foundation for Strategic Research, Vinnova, Torsten and Ragnar Söderberg Foundation, The Swedish Cancer Society, The Swedish Research Council, European Research Council, and The Swedish Childhood Cancer Fund during the conduct of the study; other support from Oxcia outside the submitted work. A. Höglund reports grants from Radiumhemmets Forskningsfond, Swedish Foundation for Strategic Research, Vinnova, Torsten and Ragnar Söderberg Foundation, The Swedish Cancer Society, The Swedish Research Council, European Research Council, and The Swedish Childhood Cancer Fund during the conduct of the study; other support from Oxcia AB outside the submitted work. B. SeashoreLudlow reports grants from Swedish Research Council(Vetenskapsrådet) during the conduct of the study. A. Nagesh Danda reports grants from Radiumhemmets Forskningsfond, Swedish Foundation for Strategic Research, Vinnova, Torsten and Ragnar Söderberg Foundation, The Swedish Cancer Society, The Swedish Research Council, European Research Council, and The Swedish Childhood Cance Fund during the conduct of the study. H. Gad reports personal fees from European Research Council during the conduct of the study. E. Wiita reports grants from Radiumhemmets Forskningsfond, Swedish Foundation for Strategic Research Vinnova, Torsten and Ragnar Söderberg Foundation, The Swedish Cancer Society The Swedish Research Council, European Research Council, and The Swedish Childhood Cancer Fund during the conduct of the study; other support from Oxcia outside the submitted work. C. Göktürk reports grants from Radiumhemmets Forskningsfond, Swedish Foundation for Strategic Research, Vinnova, Torsten and Ragnar Söderberg Foundation, The Swedish Cancer Society, The Swedish Research Council, European Research Council, and The Swedish Childhood Cancer Fund during the conduct of the study. A. Rasti reports grants from Karolinska Institutet during the conduct of the study. S. Friedrich reports grants from Radiumhemmet Forskningsfond, Swedish Foundation for Strategic Research, Vinnova, Torsten and Ragnar Söderberg Foundation, The Swedish Cancer Society, The Swedish Research Council, European Research Council, and The Swedish Childhood Cancer Fund during the conduct of the study. T. Visnes is a minority shareholder in Oxcia AB from Stockholm, who is responsible for the clinical develpoment of TH1579 a.k.a Karonudib. M. Scobie reports grants from Radiumhemmets Forskningsfond, Swedish Foundation for Strategic Research, Vinnova, Torsten and Ragnar Söderberg Foundation, The Swedish Cancer Society, The Swedish Research Council, European Research Council, and The Swedish Childhood Cancer Fund during the conduct of the study; personal fees from Oxcia $\mathrm{AB}$ outside the submitted work; in addition M. Scobie has a patent for WO2014084778 issued and licensed to Oxcia AB. T. Koolmeister reports grants from Radiumhemmets Forskningsfond, Swedish Foundation for Strategic Research, Vinnova, Torsten and Ragnar Söderberg, The Swedish Cancer Society, European Research Council, and The Swedish Childhood Cancer Fund during the conduct of the study; other support from Oxcia AB outside the submitted work; in addition, T. Koolmeister has a patent for WO 2014084778 issued and licensed to Oxcia AB. M. Henriksson reports grants from Radiumhemmets Forskningsfond, Swedish Foundation for Strategic Research, Vinnova, Torsten and Ragnar Söderberg Foundation, The Swedish Cancer Society, The Swedish Research Council, European Research Council, and The Swedish Childhood Cancer Fund during the conduct of the study; other support from Oxcia $\mathrm{AB}$ outside the submitted work; in addition, M. Henriksson has a patent for WO 2015187089 issued. O. Wallner reports grants from Radiumhemmets Forskningsfond, Swedish Foundation for Strategic Research, Vinnova, Torsten and Ragnar Söderberg Foundation, The Swedish Cancer Society, The Swedish Research Council, European Research Council, and The Swedish Childhood Cancer Fund during the conduct of the study; other support from Oxcia outside the submitted work; in addition, $\mathrm{O}$. Wallner has a patent for WO2014084778A1 issued, a patent for WO201587088A1 issued, and a patent for WO2015187089A1 issued. T. Sandvall reports grants from Radiumhemmets Forskningsfond, Swedish Foundation for Strategic Research, Vinnova, Torsten and Ragnar Söderberg Foundation, The Swedish Cancer Society, The Swedish Research Council, European Research Council, and The Swedish Childhood Cancer Fund during the conduct of the study; other support from Oxcia outside the submitted work. M.J. Garnett reports grants from Wellcome during the conduct of the study. T. Helleday reports grants from European Research Council, The Swedish Research Council, The Swedish Cancer Society, The Torsten and Ragnar Söderberg Foundation, Swedish Foundation for Strategic Research, and Vinnova during the conduct of the study; in addition, T. Helleday has a patent for MTH1 inhibitors for treatment of cancer issued to Helleday Foundation and a patent for MTH1 inhibitors for treatment of cancer licensed to Oxcia $\mathrm{AB}$; and shares in Oxcia AB. U. Warpman Berglund reports grants from Radiumhemmets Forskningsfond, Swedish Foundation for Strategic Research, European Research Council, The Swedish Research Council, The Swedish Cancer Society, Vinnova, The Torsten and Ragnar Söderberg Foundation, and Barncancerfonden during the conduct of the study; personal fees and other support from $\mathrm{Oxcia} A B$ and other support from Thomas Helleday Foundation for Medical Research outside the submitted work. No disclosures were reported by the other authors.

\section{Authors' Contributions}

K. Sanjiv: Data curation, validation, investigation, visualization, methodology, writing-original draft, writing-review and editing. J.M. Calderón-Montaño: Data curation, validation, investigation, visualization, methodology, writing-original draft, writing-review and editing. T.M. Pham: Data curation, formal analysis, validation, investigation, visualization, methodology, writing-original draft, writing-review and editing. T. Erkers: Data curation, formal analysis, validation, investigation, visualization, methodology, writing-original draft, writing-review and editing. V. Tsuber: Data curation, formal analysis, validation, investigation, visualization, writing-review and editing. I. Almlöf: Data curation, formal analysis, validation, investigation, visualization, methodology, writing-review and editing. A. Höglund: Data curation, formal analysis, validation, investigation, visualization, methodology, writing-review and editing. Y. Heshmati: Data curation, formal analysis, validation, investigation, visualization, methodology, writing-review and editing. B. Seashore-Ludlow: Data curation, formal analysis, validation, investigation, visualization, methodology, writing-review and editing. A. Nagesh Danda: Data curation, validation, investigation, methodology, writing-review and editing. H. Gad: Data curation, validation, investigation, visualization, methodology, writing-review and editing. E. Wiita: Data curation, formal analysis, validation, investigation, visualization, methodology, writing-review and editing. C. Göktürk: Data curation, formal analysis, validation, investigation, visualization, methodology, writing-review and editing. A. Rasti: Data curation, formal analysis, validation, investigation, methodology, writing-review and editing. S. Friedrich: Data curation, formal analysis, investigation, visualization, methodology, writing-review and editing. A. Centio: Data curation, validation, investigation, visualization, methodology, writing-review and editing. M. Estruch: Data curation, validation, investigation, visualization, methodology, writing-review and editing. T.K. Våtsveen: Data curation, investigation, visualization, methodology, writing-review and editing. N. Struyf: Data curation, investigation, methodology, writing-review and editing. T. Visnes: Investigation, methodology, writing-review and editing. M. Scobie: Investigation, writing-review and editing. T. Koolmeister: Investigation, writing-review and editing. M. Henriksson: Investigation, writingreview and editing. $\mathbf{O}$. Wallner: Resources, investigation, writing-review and editing. T. Sandvall: Resources, supervision, investigation, writing-review and editing. S. Lehmann: Resources, data curation. K. Theilgaard-Mönch: Resources, data curation, supervision, methodology, writing-review and editing. M.J. Garnett: Conceptualization, resources, data curation, formal analysis, supervision, investigation, methodology, writing-review and editing. P. Östling: Resources, data curation, supervision, funding acquisition, investigation, methodology, writing-review and editing. J. Walfridsson: Conceptualization, resources, data curation, formal analysis, supervision, investigation, methodology, writing-review and editing. T. Helleday: Resources, funding acquisition, investigation, methodology, writing-review and editing. U. Warpman Berglund: Conceptualization, resources, data curation, supervision, funding acquisition, validation, investigation, writing-original draft, project administration.

\section{Acknowledgments}

The authors thank MedH Core Flow Cytometry facility (Karolinska Institutet), supported by KI/SLL, for providing cell sorting services, cell analysis services, 
technical expertise, and scientific input. The authors thank the staff, particularly the research nurse Anna Bohlin, and patients at the hematology wards at the Karolinska University Hospital and the Akademiska University hospital for kindly providing samples for this study. This research was funded in whole, or in part, by the Wellcome Trust Grant 206194. For the purpose of Open Access, the author has applied a CC BY public copyright license to any Author Accepted Manuscript version arising from this submission.

This work was funded by The European Research Council (TAROX Programme, ERC-695376, T. Helleday), The Swedish Research Council (2015-00162, 2017-06095, T. Helleday), The Swedish Cancer Society (CAN2018/0658, T. Helleday), the Torsten and Ragnar Söderberg Foundation (T. Helleday), Swedish Foundation for Strategic Research (RB13-0224, U. Warpman Berglund), Radiumhemmets Forskningsfond

\section{References}

1. Lowenberg B, Downing JR, Burnett A. Acute myeloid leukemia. N Engl J Med 1999;341:1051-62.

2. Dohner H, Estey E, Grimwade D, Amadori S, Appelbaum FR, Buchner T, et al. Diagnosis and management of AML in adults: 2017 ELN recommendations from an international expert panel. Blood 2017;129:424-47.

3. Bonnet D, Dick JE. Human acute myeloid leukemia is organized as a hierarchy that originates from a primitive hematopoietic cell. Nat Med 1997;3:730-7.

4. Lapidot T, Sirard C, Vormoor J, Murdoch B, Hoang T, Caceres-Cortes J, et al. A cell initiating human acute myeloid leukaemia after transplantation into SCID mice. Nature 1994;367:645-8.

5. Ishikawa F, Yoshida S, Saito Y, Hijikata A, Kitamura H, Tanaka S, et al. Chemotherapy-resistant human AML stem cells home to and engraft within the bone-marrow endosteal region. Nat Biotechnol 2007;25:1315-21.

6. Hole PS, Zabkiewicz J, Munje C, Newton Z, Pearn L, White P, et al. Overproduction of NOX-derived ROS in AML promotes proliferation and is associated with defective oxidative stress signaling. Blood 2013; 122:3322-30.

7. Ludin A, Gur-Cohen S, Golan K, Kaufmann KB, Itkin T, Medaglia C, et al. Reactive oxygen species regulate hematopoietic stem cell self-renewal, migration and development, as well as their bone marrow microenvironment. Antioxid Redox Signal 2014;21:1605-19.

8. Sillar JR, Germon ZP, DeIuliis GN, Dun MD. The role of reactive oxygen species in acute myeloid leukaemia. Int J Mol Sci 2019;20:6003.

9. Abdel-Wahab O, Levine RL. Metabolism and the leukemic stem cell. J Exp Med 2010;207:677-80.

10. Sallmyr A, Fan J, Datta K, Kim KT, Grosu D, Shapiro P, et al. Internal tandem duplication of FLT3 (FLT3/ITD) induces increased ROS production, DNA damage, and misrepair: implications for poor prognosis in AML. Blood 2008; 111:3173-82.

11. Zhang Y, Du Y, Le W, Wang K, Kieffer N, Zhang J. Redox control of the survival of healthy and diseased cells. Antioxid Redox Signal 2011;15:2867-908.

12. Gad H, Koolmeister T, Jemth AS, Eshtad S, Jacques SA, Strom CE, et al. MTH1 inhibition eradicates cancer by preventing sanitation of the dNTP pool. Nature 2014;508:215-21.

13. Warpman Berglund U, Sanjiv K, Gad H, Kalderen C, Koolmeister T, Pham T, et al. Validation and development of MTH1 inhibitors for treatment of cancer. Ann Oncol 2016;27:2275-83.

14. Rai P, Young JJ, Burton DG, Giribaldi MG, Onder TT, Weinberg RA. Enhanced elimination of oxidized guanine nucleotides inhibits oncogenic RAS-induced DNA damage and premature senescence. Oncogene 2011;30:1489-96.

15. Burton DG, Rai P. MTH1 counteracts oncogenic oxidative stress. Oncoscience 2015;2:785-6.

16. Giribaldi MG, Munoz A, Halvorsen K, Patel A, Rai P. MTH1 expression is required for effective transformation by oncogenic HRAS. Oncotarget 2015;6: 11519-29.

17. Rai P. Human Mut T Homolog 1 (MTH1): a roadblock for the tumorsuppressive effects of oncogenic RAS-induced ROS. Small GTPases 2012;3: $120-5$.

18. Patel A, Burton DG, Halvorsen K, Balkan W, Reiner T, Perez-Stable C, et al. MutT Homolog 1 (MTH1) maintains multiple KRAS-driven pro-malignant pathways. Oncogene 2015;34:2586-96.

19. Huber KV, Salah E, Radic B, Gridling M, Elkins JM, Stukalov A, et al. Stereospecific targeting of MTH1 by (S)-crizotinib as an anticancer strategy. Nature 2014;508:222-7.
(191282, U. Warpman Berglund), The Swedish Childhood Cancer Fund (PR2018 0095, T. Helleday), Vinnova (2015-04755, T. Helleday), The Swedish Institute Visby and Danish Cancer Society (R167-A10932-17-S2, K. Theilgaard-Mönch). The Sanger screen was funded in whole, or in part, by the Wellcome Trust Grant 206194 (M.J. Garnett).

The costs of publication of this article were defrayed in part by the payment of page charges. This article must therefore be hereby marked advertisement in accordance with 18 U.S.C. Section 1734 solely to indicate this fact.

Received January 7, 2021; revised July 25, 2021; accepted September 29, 2021; published first September 30, 2021.

20. Nakabeppu Y, Tsuchimoto D, Furuichi M, Sakumi K. The defense mechanisms in mammalian cells against oxidative damage in nucleic acids and their involvement in the suppression of mutagenesis and cell death. Free Radic Res 2004;38: 423-9.

21. Patterson JC, Joughin BA, van de Kooij B, Lim DC, Lauffenburger DA, Yaffe MB. ROS and oxidative stress are elevated in mitosis during asynchronous cell cycle progression and are exacerbated by mitotic arrest. Cell Syst 2019;8:163-7.

22. Domenech E, Maestre C, Esteban-Martinez L, Partida D, Pascual R, FernandezMiranda G, et al. AMPK and PFKFB3 mediate glycolysis and survival in response to mitophagy during mitotic arrest. Nat Cell Biol 2015;17:1304-16.

23. Gad H, Mortusewics O, Rudd SG, Stolz A, Maral N, Brautigam L, et al. MTH1 promotes mitotic progression to avoid oxidative DNA damage in cancer cells. BioRxiv 2019;575290.

24. Brautigam L, Pudelko L, Jemth AS, Gad H, Narwal M, Gustafsson R, et al. Hypoxic signaling and the cellular redox tumor environment determine sensitivity to MTH1 inhibition. Cancer Res 2016;76:2366-75.

25. Das I, Gad H, Brautigam L, Pudelko L, Tuominen R, Hoiom V, et al. AXL and CAV-1 play a role for MTH1 inhibitor TH1579 sensitivity in cutaneous malignant melanoma. Cell Death Differ 2020;27:2081-98.

26. Zhou H, Jian Y, Leng Y, Liu N, Tian Y, Wang G, et al. Human MutT homologue 1 mRNA overexpression correlates to poor response of multiple myeloma. Int J Hematol 2017;105:318-25.

27. Coskun E, Jaruga P, Jemth AS, Loseva O, Scanlan LD, Tona A, et al. Addiction to MTH1 protein results in intense expression in human breast cancer tissue as measured by liquid chromatography-isotope-dilution tandem mass spectrometry. DNA Repair 2015;33:101-10.

28. McPherson LA, Troccoli CI, Ji D, Bowles AE, Gardiner ML, Mohsen MG, et al. Increased MTH1-specific 8-oxodGTPase activity is a hallmark of cancer in colon, lung and pancreatic tissue. DNA Repair 2019;83:102644.

29. Hua X, Sanjiv K, Gad H, Pham T, Gokturk C, Rasti A, et al. Karonudib is a promising anticancer therapy in hepatocellular carcinoma. Ther Adv Med Oncol 2019;11:1758835919866960

30. Einarsdottir BO, Karlsson J, Soderberg EMV, Lindberg MF, Funck-Brentano E Jespersen $\mathrm{H}$, et al. A patient-derived xenograft pre-clinical trial reveals treatment responses and a resistance mechanism to karonudib in metastatic melanoma. Cell Death Dis 2018;9:810.

31. Moukengue B, Brown HK, Charrier C, Battaglia S, Baud'huin M, Quillard T, et al. TH1579, MTH1 inhibitor, delays tumour growth and inhibits metastases development in osteosarcoma model. EBioMedicine 2020;53:102704.

32. Pudelko L, Rouhi P, Sanjiv K, Gad H, Kalderen C, Hoglund A, et al. Glioblastoma and glioblastoma stem cells are dependent on functional MTH1. Oncotarget 2017;8:84671-84

33. Patterson JC, Joughin BA, Prota AE, Muhlethaler T, Jonas OH, Whitman MA, et al. VISAGE reveals a targetable mitotic spindle vulnerability in cancer cells. Cell Syst 2019;9:74-92.

34. Rudd SG, Gad H, Sanjiv K, Amaral N, Hagenkort A, Groth P, et al. MTH1 inhibitor TH588 disturbs mitotic progression and induces mitosis-dependent accumulation of genomic 8-oxodG. Cancer Res 2020;80:3530-41.

35. Kettle JG, Alwan H, Bista M, Breed J, Davies NL, Eckersley K, et al. Potent and selective inhibitors of MTH1 probe its role in cancer cell survival. J Med Chem 2016;59:2346-61.

36. Iorio F, Knijnenburg TA, Vis DJ, Bignell GR, Menden MP, Schubert M, et al. A landscape of pharmacogenomic interactions in cancer. Cell 2016;166: $740-54$. 
Sanjiv et al.

37. Seashore-Ludlow B, Rees MG, Cheah JH, Cokol M, Price EV, Coletti ME, et al. Harnessing connectivity in a large-scale small-molecule sensitivity dataset. Cancer Discov 2015;5:1210-23.

38. Orta ML, Hoglund A, Calderon-Montano JM, Dominguez I, Burgos-Moron E, Visnes T, et al. The PARP inhibitor olaparib disrupts base excision repair of 5-aza-2'-deoxycytidine lesions. Nucleic Acids Res 2014;42:9108-20.

39. Heshmati Y, Turkoz G, Harisankar A, Kharazi S, Bostrom J, Dolatabadi $\mathrm{EK}$, et al. The chromatin-remodeling factor $\mathrm{CHD} 4$ is required for maintenance of childhood acute myeloid leukemia. Haematologica 2018;103 $1169-81$.

40. Pemovska T, Kontro M, Yadav B, Edgren H, Eldfors S, Szwajda A, et al Individualized systems medicine strategy to tailor treatments for patients with chemorefractory acute myeloid leukemia. Cancer Discov 2013;3:1416-29.

41. Yadav B, Wennerberg K, Aittokallio T, Tang J. Searching for drug synergy in complex dose-response landscapes using an interaction potency model. Comput Struct Biotechnol J 2015;13:504-13.

42. Herold N, Rudd SG, Sanjiv K, Kutzner J, Bladh J, Paulin CBJ, et al. SAMHD1 protects cancer cells from various nucleoside-based antimetabolites. Cell Cycle 2017;16:1029-38.
43. Wang JY, Jin L, Yan XG, Sherwin S, Farrelly M, Zhang YY, et al. Reactive oxygen species dictate the apoptotic response of melanoma cells to TH588. J Invest Dermatol 2016;136:2277-86.

44. Kawamura T, Kawatani M, Muroi M, Kondoh Y, Futamura Y, Aono H, et al Proteomic profiling of small-molecule inhibitors reveals dispensability of MTH1 for cancer cell survival. Sci Rep 2016;6:26521.

45. Petrocchi A, Leo E, Reyna NJ, Hamilton MM, Shi X, Parker CA, et al Identification of potent and selective MTH1 inhibitors. Bioorg Med Chem Lett 2016;26:1503-7.

46. Samaranayake GJ, Huynh M, Rai P. MTH1 as a chemotherapeutic target: the elephant in the room. Cancers 2017;9:47.

47. Dean M, Fojo T, Bates S. Tumour stem cells and drug resistance. Nat Rev Cancer 2005;5:275-84.

48. Ghelli Luserna di Rora A, Martinelli G, Simonetti G. The balance between mitotic death and mitotic slippage in acute leukemia: a new therapeutic window? J Hematol Oncol 2019;12:123.

49. Pourrajab F, Zare-Khormizi MR, Hekmatimoghaddam S, Hashemi AS. Molecular targeting and rational chemotherapy in acute myeloid leukemia. J Exp Pharmacol 2020;12:107-28. 


\section{Cancer Research}

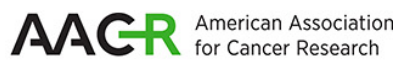

The Journal of Cancer Research (1916-1930) | The American Journal of Cancer (1931-1940)

\section{MTH1 Inhibitor TH1579 Induces Oxidative DNA Damage and Mitotic Arrest in Acute Myeloid Leukemia}

Kumar Sanjiv, José Manuel Calderón-Montaño, Therese M. Pham, et al.

Cancer Res 2021;81:5733-5744. Published OnlineFirst September 30, 2021.

Updated version Access the most recent version of this article at: doi:10.1158/0008-5472.CAN-21-0061

Supplementary Access the most recent supplemental material at:

Material http://cancerres.aacrjournals.org/content/suppl/2021/10/01/0008-5472.CAN-21-0061.DC1

Cited articles This article cites 48 articles, 8 of which you can access for free at: http://cancerres.aacrjournals.org/content/81/22/5733.full\#ref-list-1

E-mail alerts Sign up to receive free email-alerts related to this article or journal.

Reprints and To order reprints of this article or to subscribe to the journal, contact the AACR Publications Department at Subscriptions pubs@aacr.org.

Permissions To request permission to re-use all or part of this article, use this link http://cancerres.aacrjournals.org/content/81/22/5733.

Click on "Request Permissions" which will take you to the Copyright Clearance Center's (CCC) Rightslink site. 